\title{
Pengaruh Sudut Kemiringan Dan Intensitas Matahari Terhadap Karakteristik Modul Polycristaline Dengan Metode Regresi Berganda
}

\author{
Samsurizal $^{1}$, Miftahul Fikri ${ }^{2}$, Andi Makkulau ${ }^{3}$, Christiono ${ }^{4}$ \\ ${ }^{1}$ Teknik Elektro, Institut Teknologi PLN, ${ }^{2}$ Teknologi Listrik, Institut Teknologi PLN \\ ${ }^{3}$ Teknik Elektro, Institut Teknologi PLN, ${ }^{3}$ Teknik Elektro, Institut Teknologi PLN \\ samsurizal@itpln.ac.id,miftahul@itpln.ac.id,andi.mk@itpln.ac.id,christiono@itpln.ac.id
}

Coprespondent Author: samsurizal@itpln.ac.id

\begin{abstract}
- solar energy is often known by other terms solar energy is a form of renewable energy source. The potential of solar energy certainly affects the power generated in solar modules, there are several influences that cause solar energy not to be obtained optimally. In this study will be made mathematical modeling using multiple regression methods exposed to the angle of tilt and intensity of the sun with the research object of the polycristalline type solar module. The results obtained by calculating mathematically obtained the accuracy of the model with MAPE, as well as the adjusted value of $R$ square of 0.960363563 which states that the percentage of the influence of irradiation-free variables and temperature simultaneously on the current obtained is very strong. While the results of calculations with double linear regression, the value of the regression coefficient on the irradiation variable $\left(x_{-} 1\right)$ by 0.0000316 , it means that if other variables remain and irradiation variables increase by $100 \mathrm{~W} / \mathrm{m}^{2}$, then the current increases by $0.00316 \mathrm{~A}$. Then the regression coefficient on the temperature variable $\left(x \_2\right)$ by 0.010573 , this means if other variables remain and temperature variables increase by $1^{\circ} \mathrm{C}$, then the current increases by 0.010573 A. From these results, it should be known the level of accuracy of the model which in this case uses MAPE. MAPE obtained on this model is $7.046 \%$, this corresponds to the error standard of 0.007650294 with an average current measurement scale of \pm 0.1 A. Thus, the MAPE results show that the model has an accuracy of $92.954 \%$, which means that the modeling obtained is very good.

Keywords - Solar Energy, Tilt Angle, Polycristaline, Current, Multiple Regression.
\end{abstract}

ABSTRAK - Energi surya sering kita kenal dengan istilah lain energi matahari merupakan bentuk sumber energi gerbarukan. Potensi energi surya yang besar tentu mempengaruhi daya yang dihasilkan pada modul surya, terdapat beberapa pengaruh yang menyebabkan energi surya tidak diperoleh secara optimum. Pada penelitian ini akan dibuatkan pemodelan matematis dengan menggunakan metode regresi bergadanda terdahap sudut kemiringan dan intensitas matahari dengan objek penelitian modul surya jenis polycristalline. Hasil yang diperoleh dengan menghitung secara matematis diperoleh keakurasian model dengan MAPE, serta nilai adjusted $\mathrm{R}$ square sebesar 0.960363563 yang menyatakan bahwa persentase pengaruh variabel bebas iradiasi dan suhu secara serentak terhadap arus yang diperoleh sangat kuat. Sedangkan hasil perhitungan dengan regresi linear berganda, nilai koefisien regresi pada variabel iradiasi (x_1) sebesar 0.0000316, hal tersebut berarti jika variabel lain tetap dan variabel iradiasi bertambah sebesar $100 \mathrm{~W} / \mathrm{m}^{2}$, maka arus bertambah senilai 0.00316 A. Kemudian koefisien regresi pada variabel suhu ( $\left.\mathrm{x} \_2\right)$ sebesar 0.010573 , hal ini berarti apabila variabel lain tetap dan variabel suhu bertambah sebesar $1^{\circ} \mathrm{C}$, maka arus bertambah 0.010573 A. Dari hasil-hasil tersebut, harus diketahui tingkat keakurasian model yang mana dalam hal ini menggunakan MAPE. MAPE yang diperoleh pada model ini sebesar 7.046\%, hal ini bersesuaian dengan standar eror sebesar 0.007650294 dengan skala pengukuran rata-rata arus sebesar $\pm 0.1 \mathrm{~A}$. Dengan begitu, hasil MAPE tersebut menunjukkan bahwa model memiliki keakuratan sebesar $92.954 \%$, yang artinya pemodelan yang diperoleh sangat baik.

Kata Kunci - Energi Surya, Sudut Kemiringan, Polycristaline, Arus, Regresi Berganda.

\section{PENDAHULUAN}

Indonesia merupakan negeri dengan potensi energi matahari dengan rata-rata potensi energi $4,80 \mathrm{kWh} / \mathrm{m}^{2} /$ hari. Seiring dengan berkembangnya teknologi konversi energi surya menjadi energi listrik serta menurunnya biaya peralatan yang diperlukan, potensi energi surya nasional menjadi hal yang layak untuk didorong pemanfaatannya di Indonesia. Pemenuhan kebutuhan energi listrik saat ini masih bergantung pada sumber energi fosil yang ketersediaanya terbatas. Oleh karena itu dimasa mendatang pemanfaatan sumber energi terbarukan merupakan alternatif yang perlu terus dikembangkan.

Sumber daya energi terbarukan memiliki sifat terbarukan dan berkesinambungan. Energi matahari merupakan sumber utama Pembangkit Listrik Tenaga Surya (PLTS) termasuk bagian dari energi terbarukan. Komponen utamanya ialah sel surya. Umumnya sering digunakan pada daerah dengan paparan radiasi matahari yang tinggi serta daerah yang belum tersentuh oleh aliran listrik. Jenis sel surya yang sering kita jumpai dan banyak diterapkan adalah jenis polikristaline silicon.

Di penelitian sebelumnya pada Jurnal Energi dan Kelistrikan[8] diperoleh hasil adanya pengaruh Sudut kemiringan terhadap intensitas matahari yang mempengaruhi output dari PV array sehingga untuk mendeteksi efek tersebut digunakan metode observasi langsung dan validaasi. Sedangkan penelitian lainya [9] diperoleh hasil jika semakin besar sudut pada modul surya akan menyebabkan penurunan kinerja modul surya. 
Diperoleh pula adanya pengaruh irradiance dipenelitian tersebut. Pada penelitian lainnya (Makkulau, et all) menghasilkan arus optimal ialah sebesar 1,92 Ampere dengan suhu optimal sebesar $37,4^{\circ} \mathrm{C}$, dan nilai tukar tertinggi adalah pada 2,08 Ampere sedangkan suhu pada permukaan modul surya sebesar $37,4^{\circ} \mathrm{C}$.

Ada beberapa parameter-pamater yang mempengaruhi kinerja modul solar diantaranya lingkungan yang dapat mempengaruhi optimalisasi modul surya diantaranya bayangan, oleh karena itu perlu dikaji sejauh mana pengaruh sudut kemiringan serta intensitas matahari terhadap karakteristik modul surya menggunakan model matematis, dengan fokus penelitian menggunakan modul surya jenis polycristaline.

\section{METODE PENELITIAN}

\subsection{Langkah Penelitian}

Secara sederhana, langkah dari penelitian ini dapat dilihat pada diagram alir pada Gambar 1.

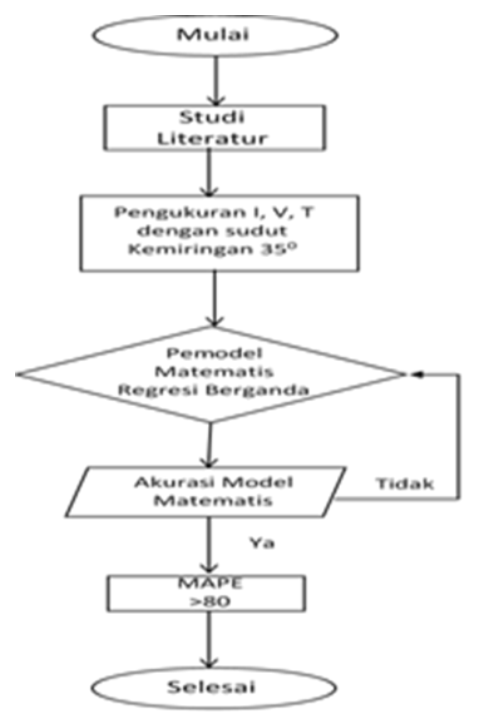

Gambar 1. Diagram Alir Penelitian.

\subsection{Analisa Penelitian}

Dalam menganalisa hasil yang didapat selanjutnya dilakukan pemodelan secara matematis yaitu dengan regresi linier berganda. Regresi berganda merupakan model regresi dengan melibatkan lebih dari satu variabel bebas. Bentuk umum persamaan regresi berganda berikut:

$$
Y=\beta_{0}+\beta_{1} \quad X_{1}+\beta_{2} X_{2}+\varepsilon
$$

dengan :

$X_{1}$ merupakan sudut kemiringan

$X_{2}$ merupakan Intensitas cahaya matahari

$Y$ adalah arus keluaran PV $\beta_{0}, \beta_{1}, \beta_{2}$ adalah parameter-parameter regresi

$\varepsilon$ adalah galat / penyimpangan

yang mana nantinya ada didapat beberapa koefisien pada variabel-variabel yang terdapat pada persamaan diatas. Dari situ juga akan didapat analisis secara teknis karena adanya keterkaitan dengan data-data yang didapat. Selain itu juga keakurasian model diperhitungkan dengan MAPE,

Mean Absolute Percentage Error (MAPE) ialah pengukuran kesalahan dengan menghitung ukuran presentase penyimpangan antara data aktual dengan data peramalan. Model yang diperoleh perlu dilihat sejauh mana akurasinya dengan menggunkan MAPE. Untuk ukuran akurasi relatif yang digunakan dengan mengetahui persentase penyimpangan dari model matematis yang dibuat.

Menurut Pakaja (2012), Mean Absolute Percentage Error (MAPE) dihitung dengan menggunakan kesalahan absolut pada tiap periode dibagi dengan nilai observasi yang nyata untuk periode itu. Selanjutnya, dengan menghitung rata-rata kesalahan persentase absolut tersebut dengan persamaan sebagai berikut.

MAPE $=\frac{1}{n} \sum_{t=1}^{n}\left|\frac{Y_{t}-\hat{Y}_{t}}{Y_{t}}\right| \times 100$

Dengan menggunakan persamaan 2 dimasukkan angkaangka yang nantinya akan dihitung dan didapat nilai mutlaknya. Dari persamaan tersebut juga didapat persentase error. Nilai error ini pun memiliki standar sebagai acuan baik atau tidaknya hasil. Dengan begitu nantinya diketahui seberapa akurat hasil yang didapat dengan model matematis yang digunakan (dalam hal ini yaitu regresi linear berganda). Kemampuan peramalan sangat baik jika memiliki nilai MAPE kurang dari $10 \%$ dan mempunyai kemampuan peramalan yang baik jika nilai MAPE kurang dari $20 \%$.

\section{HASIL DAN PEMBAHASAN}

Pengambilan data yang telah dilaksanakan selama kurun waktu kurang lebih 40 hari dengan metode pengambilan data yang dilakukan adalah observasi langsung di lapangan sehingga data yang di peroleh adalah primer hasil pengamatan secara langsung dan real time dengan durasi pencatatan data di lakukan tiap 10 menit untuk jangka waktu 8 jam perhari, Adapun data yang diperoleh antara lain adalah data arus keluaran dari modul surya, tegangan keluaran modul surya, irradiasi pancaran sinar matahari, dan suhu pada permukaan modul surya dari tiap-tiap perubahan sudut kemiringan modul surya. Adapun data eksternal yang digunakan ialah data perubahan iklim lokal selama proses 
pengamatan yang memiliki dampak secara langsung terhadap perubahan karakteristik data dari modul surya.

Setelah mencatat semua hasil pengukuran dalam satu hari, selanjutnya dilakukan penginputan data pada aplikasi microsoft excel agar dapat memudahkan peneliti dalam pengolahan dan pengelompokan data.

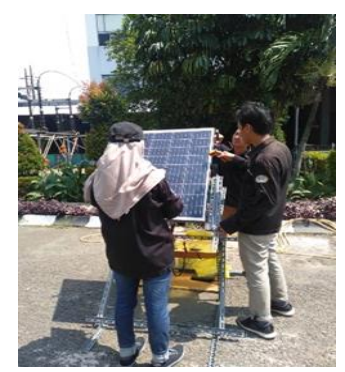

Gambar 2. Proses Pengambilan Data

Berdasarkan hasil pengamatan pada pembangkit listrik tenaga surya (PLTS), dengan satuan waktu pengambilan data 10 menit, diperoleh data iradiasi, suhu dan arus sebanyak 48 datum yang dimulai pada pukul 08.00 WIB s.d. 16.00 WIB sebagai berikut:

Tabel 1. Hasil Pengukuran

\begin{tabular}{|c|c|c|c|c|}
\hline No & Jam & $\begin{array}{c}\text { I. Radiasi } \\
\left(\mathbf{W} / \mathbf{m}^{\mathbf{2}}\right)\end{array}$ & $\begin{array}{c}\text { Suhu } \\
\left({ }^{\mathbf{O}} \mathbf{C}\right)\end{array}$ & $\begin{array}{c}\text { Arus } \\
(\mathbf{A})\end{array}$ \\
\hline 1 & $08.00-08.10$ & 61 & 25.4 & 0.05 \\
\hline 2 & $08.10-08.20$ & 51 & 25.2 & 0.05 \\
\hline 3 & $08.20-08.30$ & 50 & 25.1 & 0.06 \\
\hline 4 & $08.30-08.40$ & 56 & 25.1 & 0.04 \\
\hline 5 & $08.40-08.50$ & 66 & 25.2 & 0.05 \\
\hline 6 & $08.50-09.00$ & 76 & 25.2 & 0.04 \\
\hline 7 & $09.00-09.10$ & 85 & 25.2 & 0.05 \\
\hline 8 & $09.10-09.20$ & 91 & 25.2 & 0.04 \\
\hline 9 & $09.20-09.30$ & 114 & 25.5 & 0.06 \\
\hline 10 & $09.30-09.40$ & 143 & 25.5 & 0.05 \\
\hline 11 & $09.40-09.50$ & 160 & 26.4 & 0.08 \\
\hline 12 & $09.50-10.00$ & 195 & 26.2 & 0.07 \\
\hline 13 & $10.00-10.10$ & 205 & 26.8 & 0.06 \\
\hline 14 & $10.10-10.20$ & 215 & 26.3 & 0.05 \\
\hline 15 & $10.20-10.30$ & 188 & 27.2 & 0.08 \\
\hline 16 & $10.30-10.40$ & 202 & 27.3 & 0.08 \\
\hline 17 & $10.40-10.50$ & 228 & 27.9 & 0.08 \\
\hline 18 & $10.50-11.00$ & 245 & 28.1 & 0.08 \\
\hline 19 & $11.00-11.10$ & 337 & 29.2 & 0.11 \\
\hline 20 & $11.10-11.20$ & 471 & 31.8 & 0.14 \\
\hline 21 & $11.20-11.30$ & 481 & 32.4 & 0.14 \\
\hline 22 & $11.30-11.40$ & 502 & 32.9 & 0.14 \\
\hline 23 & $11.40-10.50$ & 400 & 32 & 0.14 \\
\hline
\end{tabular}

\begin{tabular}{|c|c|c|c|c|}
\hline No & Jam & $\begin{array}{c}\text { I. Radiasi } \\
\left(\mathbf{W} / \mathbf{m}^{2}\right)\end{array}$ & $\begin{array}{l}\text { Suhu } \\
\left({ }^{\mathbf{O}} \mathrm{C}\right)\end{array}$ & $\begin{array}{c}\text { Arus } \\
\text { (A) }\end{array}$ \\
\hline 24 & $11.50-12.00$ & 385 & 32 & 0.13 \\
\hline 25 & $12.00-12.10$ & 394 & 33.8 & 0.15 \\
\hline 26 & $12.10-12.20$ & 398 & 34.3 & 0.15 \\
\hline 27 & $12.20-12.30$ & 328 & 33.9 & 0.14 \\
\hline 28 & $12.30-12.40$ & 402 & 33.9 & 0.15 \\
\hline 29 & $12.40-12.50$ & 362 & 33.3 & 0.15 \\
\hline 30 & $12.50-13.00$ & 357 & 33.8 & 0.14 \\
\hline 31 & $13.00-13.10$ & 357 & 34.2 & 0.16 \\
\hline 32 & $13.10-13.20$ & 320 & 33.5 & 0.13 \\
\hline 33 & $13.20-13.30$ & 76 & 32.8 & 0.13 \\
\hline 34 & $13.30-13.40$ & 71 & 32 & 0.12 \\
\hline 35 & $13.40-13.50$ & 258 & 32.4 & 0.13 \\
\hline 36 & $13.50-14.00$ & 241 & 31.6 & 0.12 \\
\hline 37 & $14.00-14.00$ & 233 & 31.7 & 0.12 \\
\hline 38 & $14.10-14.20$ & 212 & 31.5 & 0.12 \\
\hline 39 & $14.20-14.30$ & 218 & 31.5 & 0.12 \\
\hline 40 & $14.30-14.40$ & 248 & 31.6 & 0.12 \\
\hline 41 & $14.40-14.50$ & 246 & 31.5 & 0.11 \\
\hline 42 & $14.50-15.00$ & 307 & 32.1 & 0.13 \\
\hline 43 & $15.00-15.10$ & 332 & 33.2 & 0.15 \\
\hline 44 & $15.10-15.20$ & 220 & 32.9 & 0.15 \\
\hline 45 & $15.20-15.30$ & 148 & 31.8 & 0.13 \\
\hline 46 & $15.30-15.40$ & 123 & 31.2 & 0.12 \\
\hline 47 & $15.40-15.50$ & 138 & 31.2 & 0.12 \\
\hline 48 & $15.50-16.00$ & 173 & 31.7 & 0.11 \\
\hline
\end{tabular}

Data diatas kemudian dibuat model menggunakan regresi linear berganda dengan variabel tak-bebas arus (y), serta variabel bebas iradiasi (x1), dan suhu (x2). Adapun hasil yang diperoleh terangkum sebagai berikut:

\begin{tabular}{lr}
\multicolumn{2}{l}{ SUMMARY OUTPUT } \\
\begin{tabular}{lr}
\multicolumn{1}{c}{ Regression } \\
Statistics
\end{tabular} \\
\hline Multiple R & 0.980841588 \\
R Square & 0.96205022 \\
Adjusted R Square & 0.960363563 \\
Standard Error & 0.007650294 \\
Observations & 48 \\
\hline
\end{tabular}

\begin{tabular}{|c|c|c|c|c|c|c|}
\hline & $d f$ & SS & $M S$ & $F$ & $\begin{array}{c}\text { Significance } \\
F\end{array}$ & \\
\hline Regression & 2 & 0.066766285 & 0.033383143 & 570.3888167 & $1.07698 \mathrm{E}-32$ & \\
\hline Residual & 45 & 0.002633715 & $5.8527 \mathrm{E}-05$ & & & \\
\hline \multirow[t]{2}{*}{ Total } & 47 & 0.0694 & & & & \\
\hline & Coefficients & Standard Error & $t$ Stat & $P$-value & Lower 95\% & Upp \\
\hline Intercept & -0.21964596 & 0.01249608 & -17.5771897 & $8.85095 \mathrm{E}-22$ & 0.244814356 & 0.194 \\
\hline $\mathrm{X}$ Variable 1 & 3.16033E-05 & $1.23767 \mathrm{E}-05$ & 2.553454583 & 0.014125082 & $6.67539 \mathrm{E}-06$ & $5.65:$ \\
\hline $\mathrm{X}$ Variable 2 & 0.010572738 & 0.000476469 & 22.18979049 & $7.19275 \mathrm{E}-26$ & 0.009613081 & 0.011 \\
\hline
\end{tabular}


Berdasarkan hasil di atas, diperoleh hasil dan penjelasan sebagai berikut

\section{Koefisien Determinasi}

Hasil "adjusted R square" sebesar 0.960363563, hal ini berarti bahwa persentase pengaruh variable bebas iradiasi dan suhu secara serentak terhadap arus yang diperoleh PLTS sangat kuat.

\section{Persamaan regresi}

Persamaan menggunakan persamaan 1. Maka didapatkan model regresi linear berganda yang diperoleh adalah

$$
y=-0.219646+0.0000316 x_{1}+0.010573 x_{2}
$$

Koefisien regresi pada variabel iradiasi $\left(\mathrm{x}_{1}\right)$ sebesar 0.0000316 , hal ini berarti bahwa jika variabel lain tetap dan variabel iradiasi bertambah sebesar $100 \mathrm{~W} / \mathrm{m}^{2}$, maka arus bertambah 0.00316 A. Kemudian Koefisien regresi pada variabel suhu $\left(\mathrm{x}_{2}\right)$ sebesar 0.010573 , hal ini berarti bahwa jika variabel lain tetap dan variabel suhu bertambah sebesar $1^{\circ} \mathrm{c}$, maka arus bertambah $0.010573 \mathrm{~A}$.

\section{Akurasi Model}

Berdasarkan persamaan regresi pada persamaan (1), dibangitkan data (arus dugaan) dan dihitung eror sebagai berikut:

\begin{tabular}{|c|c|c|c|}
\hline No. & Arus (A) & $\begin{array}{c}\text { Arus Dugaan } \\
(\mathrm{A})\end{array}$ & Eror \\
\hline 1 & 0.05 & 0.050829387 & 0.01658773 \\
\hline 2 & 0.05 & 0.048398806 & 0.032023882 \\
\hline 3 & 0.06 & 0.047309929 & 0.211501187 \\
\hline 4 & 0.04 & 0.047499549 & 0.187488715 \\
\hline 5 & 0.05 & 0.048872855 & 0.022542892 \\
\hline 6 & 0.04 & 0.049188888 & 0.22972221 \\
\hline 7 & 0.05 & 0.049473318 & 0.010533638 \\
\hline 8 & 0.04 & 0.049662938 & 0.241573448 \\
\hline 9 & 0.06 & 0.053561635 & 0.10730608 \\
\hline 10 & 0.05 & 0.054478131 & 0.089562618 \\
\hline 11 & 0.08 & 0.064530851 & 0.19336436 \\
\hline 12 & 0.07 & 0.063522419 & 0.09253687 \\
\hline 13 & 0.06 & 0.070182095 & 0.169701582 \\
\hline 14 & 0.05 & 0.065211759 & 0.304235178 \\
\hline 15 & 0.08 & 0.073873934 & 0.076575825 \\
\hline 16 & 0.08 & 0.075373654 & 0.057829325 \\
\hline 17 & 0.08 & 0.082538983 & 0.031737282 \\
\hline 18 & 0.08 & 0.085190786 & 0.064884829 \\
\hline 19 & 0.11 & 0.099728302 & 0.093379075 \\
\hline 20 & 0.14 & 0.131452263 & 0.061055266 \\
\hline 21 & 0.14 & 0.138111939 & 0.013486154 \\
\hline
\end{tabular}

\begin{tabular}{|c|c|c|c|}
\hline No. & Arus (A) & $\begin{array}{c}\text { Arus Dugaan } \\
\text { (A) }\end{array}$ & Eror \\
\hline 22 & 0.14 & 0.144061977 & 0.02901412 \\
\hline 23 & 0.14 & 0.131322976 & 0.061978743 \\
\hline 24 & 0.13 & 0.130848927 & 0.006530204 \\
\hline 25 & 0.15 & 0.150164285 & 0.001095231 \\
\hline 26 & 0.15 & 0.155577067 & 0.037180445 \\
\hline 27 & 0.14 & 0.149135741 & 0.06525529 \\
\hline 28 & 0.15 & 0.151474385 & 0.009829232 \\
\hline 29 & 0.15 & 0.14386661 & 0.040889267 \\
\hline 30 & 0.14 & 0.148994963 & 0.064249732 \\
\hline 31 & 0.16 & 0.153224058 & 0.042349639 \\
\hline 32 & 0.13 & 0.144653819 & 0.112721685 \\
\hline 33 & 0.13 & 0.129541697 & 0.003525406 \\
\hline 34 & 0.12 & 0.12092549 & 0.007712419 \\
\hline 35 & 0.13 & 0.131064403 & 0.008187712 \\
\hline 36 & 0.12 & 0.122068956 & 0.017241301 \\
\hline 37 & 0.12 & 0.122873404 & 0.023945029 \\
\hline 38 & 0.12 & 0.120095187 & 0.000793222 \\
\hline 39 & 0.12 & 0.120284806 & 0.002373387 \\
\hline 40 & 0.12 & 0.122290179 & 0.019084827 \\
\hline 41 & 0.11 & 0.121169699 & 0.101542716 \\
\hline 42 & 0.13 & 0.129441143 & 0.004298901 \\
\hline 43 & 0.15 & 0.141861237 & 0.054258419 \\
\hline 44 & 0.15 & 0.135149846 & 0.099001025 \\
\hline 45 & 0.13 & 0.121244397 & 0.067350794 \\
\hline 46 & 0.12 & 0.114110672 & 0.049077738 \\
\hline 47 & 0.12 & 0.114584721 & 0.045127325 \\
\hline 48 & 0.11 & 0.120977206 & 0.099792777 \\
\hline
\end{tabular}

Model yang didadapat perlu hitung serta dilihat tingkat akurasinya dengan menggunakan pendekatan MAPE. MAPE digunakan untuk menunjukkan akurasi relatif serta persentase penyimpangan dari model matematis yang digunakan. Dengan menggunakan persamaan 2 maka didapatkan hasil dengan $n=48, \mathrm{Y}_{\mathrm{t}}$ dan $\hat{Y}_{t}$ merupakan data arus dan arus dugaan pada saat $\mathrm{t}=1,2, \ldots, \mathrm{n}$. MAPE yang diperoleh pada model ini sebesar $7.046 \%$, hal ini bersesuaian dengan standar eror sebesar 0.007650294 dengan skala pengukuran rata-rata arus sebesar $\pm 0.1 \mathrm{~A}$. Hasil ini menunjukkan bahwa model memiliki keakuratan sebesar 92.954\%, yang berarti bahwa model yang diperoleh sangat baik. 


\section{KESIMPULAN}

Adapun hasil yang dapat disimpulkan dari hasil penelitian ini berdasarkan penjelasan dan perhitungan sebelumnya adalah:

1. Karakteristik sensitivitas sel surya type monocristaline dan polycristaline memiliki perbedaan yang mendasar terhadap kenaikan suhu, perubahan sudut, dan efektifitas dalam mengkonversi iradiasi sinar matahari menjadi energi listrik.

2. Perubahan sudut kemiringan dari modul surya juga berperan penting dalam mempengaruhi kinerja dari modul surya jenis polycristaline.

3. Faktor iklim juga sangat berpengaruh besar terhadap kualitas keluaran dari modul surya.

4. Nilai koefisien regresi linear berganda pada masingmasing variabel berbeda dan memengaruhi kenaikkan nilai arus PLTS yang dihasilkan dan tingkat keakurasian model yaitu sebesar $92.954 \%$, yang berarti bahwa model yang diperoleh sangat baik

\section{DAFTAR ACUAN}

[1] APAMSI, Tim. (2013). Pengembangan PLTS di Indonesia. Yogyakarta.

[2] BMTI, Tim. (2008). ET Pengenalan teknologi PLTS. Bandung

[3] Hidayat, Rian. (2013). Kajian penggunaan modul surya Thinfilm untuk PLTS di Indonesia. Jakarta. Institut Teknologi PLN

[4] Oktaviana, Rince. (2014). Studi Pengembangan PLTS dengan optimalisasi jumlah Inverter di Indonesia. Jakarta. Institut Teknologi PLN

[5] PD, Harry. (2013). Studi tekno PLTS Thermal di Indonesia. Bandung. Jurnal Ilmiah

[6] Permata Merga Kreasi, PT. (2011). Perencanaan industri sel surya thin-film. Jakarta: Badan Pengkajian dan Penerapan Teknologi

[7] Prasetyawan, Mahadi. (2012). Modul Praktikum Penyinaran Sebagian dan Penuh pada Photovoltaic Jenis Monocristalline. Semarang: Universitas Diponegoro

[8] Samsurizal, Andi Makkulau, Christiono. 2019. Analisis Pengaruh Sudut Kemiringan Terhadap Arus Keluaran Pada Photovoltaic Dengan Menggunakan Regretion Quadratic Method, Jurnal Energi \& Kelistrikan Vol. 10 No.2

[9] Samsurizal, Christiono, Andi Makkulau. (2019). Evaluasi Sudut Kemiringan Terhadap Pengaruh Irradiance Pada Array Photovoltaic Jenis Monocristalline. Jurnal SETRUM. Vol.8 No.1

[10] Chin, Chia. (2013). Effect of Partially shaded conditions on Photovoltaic Array MPPT. University Malaysia Sabah.

[11] Kho Hie Khwee. 2013. Pengaruh Temperatur Terhadap Kapasitas Daya Panel Surya (Studi Kasus: Pontianak). Jurnal ELKHA Vol.5, No 2.

[12] Makridakis, S., Wheelwright S.C, McGee V. dan McGee, E. (1999). Metode dan Aplikasi Peramalan. Alih Bahasa: Ir. Untung Sus Adriyanto, M.Sc dan Ir. Abdul Basith, M.Sc. Edisi Kedua Jilid Satu. Jakarta: Erlangga.

[13] Pakaja, F., Naba, A., Purwanto. (2012), Peramalan Penjualan Mobil Menggunakan Jaringan Syaraf Tiruan dan Certainty Factor, Jurnal EECCIS, Vol.6, No.1.
[14] Makkulau, Christiono and Samsurizal. (2019), Characteristics of Temperature Changes Measurement on Photovoltaic Surfaces Against Quality of Output Current on Solar Power Plants, International Conference on Technologies and Policies in Electric Power \& Energy, IEEE, vol. doi: 10.1109/IEEECONF48524.2019.9102630., pp. 1-4.

[15] B. S. M. Fikri dan I. P. Purnaba, (2016). Pendugaan Parameter dan Kekonvergenan Penduga Parameter Model Poisson Hidden Markov. Jurnal Matematika dan Aplikasinya, vol. 15, no. 1, pp. 45-54.

[16] Fikri, M., dan Samsurizal, S. (2020). Pemodelan Cuaca Menggunakan Model Hidden Markov Untuk Pemanfaatan Energi Surya. KILAT, Vol.9 No.2, hal.217-224. 